Policy Research Working Paper 2668

Comparative Life Expectancy in Africa

\author{
F. Desmond McCarthy \\ Holger Wolf
}

Health outcomes are

positively correlated with income, but the link is far from uniform. The key variables associated with good health outcomes fontrolling for health expenditures) are access rates - to health services, to clean water and sanitation, and to education, particularly for women.

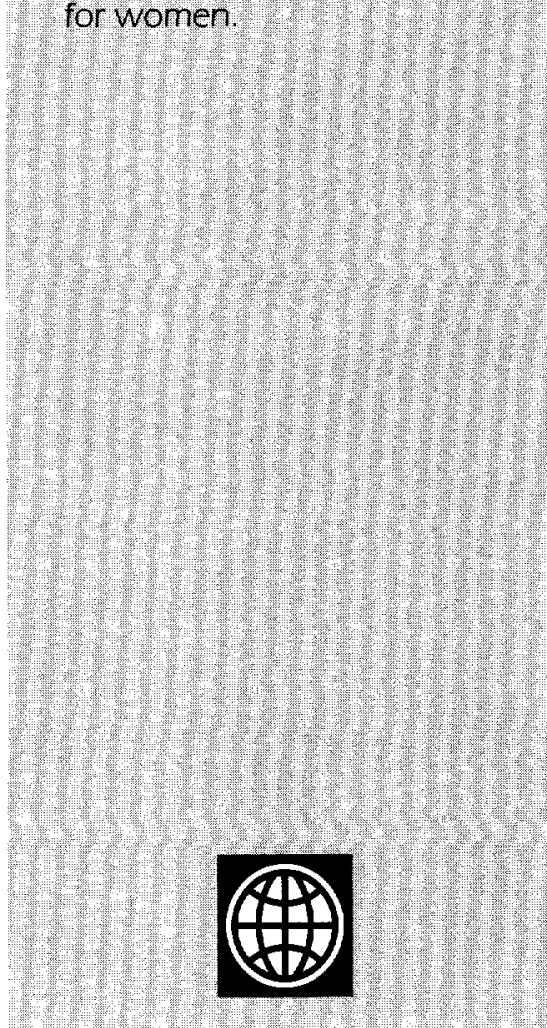

The World Bank

Development Research Group

Public Service Delivery

August 2001 
Policy Research Working Paper 2668

\section{Summary findings}

For health outcomes, is poverty destiny? McCarthy and Wolf explore this question for life expectancy in Africa, where health outcomes are positively correlated with income, but where the link is far from uniform. The key variables associated with good health outcomes (controlling for health expenditures) are access ratesto health services, to clean water and sanitation, and to education, particularly for women.

Health expenditure, either as percentage of GNP or per capita, is not a good predictor of health outcomes

(endogeneity aside). The tenuous link among health expenditures, health service outputs, and health outcomes suggests marked differences in the mapping from spending to services and from services to outcomes. While few conclusions can be drawn on the aggregate level, the patterns raise questions about what share of public expenditure should be devoted to preventive as opposed to curative measures, and the relative importance of sanitation infrastructure versus traditional health care.

This paper-a product of Public Service Delivery, Development Research Group—is part of a larger effort in the group to study the health-environment-economy nexus. The study was funded by the Bank's Research Support Budget under the research project "Health, Environment, and the Economy" (RPO 683-73). Copies of this paper are available free from the World Bank, 1818 H Street NW, Washington, DC 20433. Please contact Hedy Sladovich, room MC3-607, telephone 202473-7698, fax 202-522-1153, email address hsladovich@worldbank.org. Policy Research Working Papers are also posted on the Web at http://econ.worldbank.org. The authors may be contacted at fmccarthy@worldbank.org or hwolf@gwu.edu. August 2001. (17 pages)

The Policy Research Working Paper Series disseminates the findings of work in progress to encourage the exchange of ideas about development issues. An objective of the series is to get the findings out quickly, even if the presentations are less than fully polished. The papers carry the names of the authors and should be cited accordingly. The findings, interpretations, and conclusions expressed in this paper are entirely those of the authors. They do not necessarily represent the view of the World Bank, its Executive Directors, or the countries they represent. 


\title{
Comparative Life Expectancy in Africa
}

\author{
F. Desmond McCarthy \\ World Bank \\ Holger Wolf \\ George Washington University and NBER
}





\section{Introduction}

Rising incomes and improving medical technology have lifted health standards in most countries, alongside other indicators of the quality of life [Easterly (1999)]. Policies fostering growth are thus accompanied by indirect health benefits. Yet, income per capita is only part of the story. Health indicators differ dramatically between countries with similar income levels located in close proximity: within the group of low-income countries (under $\$ 1000$ GNP per capita) Sub-Saharan Africa, life expectancy ranges from 38 in Guinea-Bissau to 58 in Kenya (World Health Report 1999).

These observations suggest that sizeable health improvements can be obtained at current income levels by adopting best practices within the peer group of countries on similar development levels. In this chapter, we explore the size of these potential gains in terms of life expectancy for a sample of African countries. ${ }^{1}$ We focus on documenting existing disparities and inquiring whether these are related to observable country characteristics. While causality may at times be intuitive (such as for a positive link between life expectancy and access to safe water), it is not our focus, and indeed would be more convincingly tested in a time series/panel framework. We also abstract from the important cross-border aspects of disease and health policies [Sachs (2000)].

\section{A Simple Decomposition}

We begin with a simple decomposition aiming to differentiate the life expectancy differences within low income African countries, all African countries, and all countries worldwide. Our empirical analysis is straightforward. The measure of interest is the difference between the highest life expectancy among all sample countries and the life expectancy within a particular low-income country in Africa. We then decompose this

\footnotetext{
1 The focus on a single continent is motivated by the desire to keep the ceteris paribus assumption reasonably applicable. The prevalence of many common diseases in poorer economies is significantly influenced by a myriad of environmental factors including prevalence of transmitting insects, temperature
} 
health gap into three parts. The first part is the intra-group difference between the country in question and the low-income African country with the highest life expectancy. The second part is the difference this reference country and the African country (at any income level) with the highest life expectancy. The third part is the difference between the African country with the highest life expectancy and the highest life expectancy world wide.

For illustration, table 1 reports the decomposition for Niger, with a life expectancy of 47 years, compared to 58 years in Kenya (the low income African country with the highest life expectancy), 71 years in Mauritius (the African country with the highest life expectancy) and 80 years in Japan (the country with the longest life expectancy globally).

\section{Table 1: Life Expectancy in Niger}

Life Expectancy in Niger $\quad 47$

Gain from catching up to highest life expectancy in peer group $\quad+11$

Additional Gain from catching up to highest life expectancy in Africa +13

Additional Gain from catching up to highest life expectancy globally $\quad+9$

The division allows a direct comparison of the gains of moving to the level of the best local health performer within the same income group with the gains from moving up to regional and global best performers. The latter two comparison countries typically have substantially higher income levels, the second and third gain component are thus likely to partly capture the indirect gains along the development path alluded to above.

Table 2-1 reports the three gaps for all countries in the low-income group. The differences in life expectancy within the low-income group are marked, there is no uniform link between income per capita and life expectancy. The gap between the highest life expectancy within the group of low income countries and the highest life expectancy in all of Africa is commensurate with the within-group gap for about half of the low 
income countries, providing prima facie evidence for substantial potential health gains obtainable at unchanged income levels for many low income countries.

The second difference can be interpreted as the potential medium term gain from best practice economic and health policies within a broader spatially defined peer group, while the third difference captures the more distant potential gains from long term development, assuming convergence. The table suggests that the sum of the first two gaps accounts for the lion's share of the overall gap.

A look at the country with the highest life expectancy, Mauritius, is suggestive of the factors that may be associated with sustained gains in life expectancy: stable growth, absence of civil conflicts, low military expenditures and nearly universal access to clean water and sanitation; perhaps even more notable is that 99 per cent of the population has access to health facilities. Of course, the comparability of Mauritius to continental African countries is limited by geography. As an island it is less subject to some insect born diseases, nor does it suffer from cross-border river pollution. Small geographic and population size also arguably ease the challenge of providing access to water and health care. $^{2}$

\footnotetext{
less important

${ }^{2}$ Effective access may also differ by season, depending on the quality and density of the road/transportation network.
} 
Table 2. Life Expectancy Gaps

\begin{tabular}{|c|c|c|c|c|}
\hline $\begin{array}{c}\text { GNPin } 1999 \\
\text { US\$PPP }\end{array}$ & $\begin{array}{l}\text { Life } \\
\text { Expectancy at } \\
\text { Eirth }\end{array}$ & $\begin{array}{l}\text { Gep to Highest } \\
\text { life expectency } \\
\text { in the low } \\
\text { income grap }\end{array}$ & $\begin{array}{l}\text { Cap to highest } \\
\text { life expectancy } \\
\text { in Africa }\end{array}$ & $\begin{array}{l}\text { Gap to highest } \\
\text { life expectancy } \\
\text { globally }\end{array}$ \\
\hline 384 & 520 & 6.4 & 13.0 & 9.0 \\
\hline 414 & 39.8 & 18.6 & 13.0 & 9.0 \\
\hline 478 & 50.9 & 7.5 & 13.0 & 9.0 \\
\hline 553 & 49.5 & 8.9 & 13.0 & 9.0 \\
\hline 576 & 39.2 & 19.2 & 13.0 & 9.0 \\
\hline 581 & 43.2 & 15.2 & 13.0 & 9.0 \\
\hline 595 & 38.4 & 20.0 & 13.0 & 9.0 \\
\hline 599 & 49.0 & 9.4 & 13.0 & 9.0 \\
\hline 632 & 47.3 & 11.1 & 13.0 & 9.0 \\
\hline 686 & 45.6 & 128 & 13.0 & 9.0 \\
\hline 693 & 49.6 & 8.8 & 13.0 & 9.0 \\
\hline 727 & 46.6 & 11.8 & 13.0 & 9. \\
\hline 744 & 528 & 5.6 & 13.0 & 9 \\
\hline 766 & 520 & 6.4 & 13.0 & D \\
\hline 797 & 46.5 & 11.9 & 13.0 & D \\
\hline 816 & 48.1 & 10.3 & 13.0 & 0 \\
\hline 886 & 50.2 & 8.2 & 130 & b \\
\hline 897 & 51.0 & 7.4 & 13.0 & 0 \\
\hline 898 & 48.7 & 9.7 & 130 & 9.0 \\
\hline $9 \sqrt{5}$ & 58.4 & 0.0 & 130 & 9.0 \\
\hline
\end{tabular}




\section{Correlates Of Health Outcomes}

The table suggests that poverty may not be destiny as far as health outcomes are concerned: countries with very low per capita incomes, such as Tanzania, boast life expectancy comparable with those in much richer economies. It is of evident interest to ascertain whether such intra-group differences are random or are robustly associated with observable country characteristics.

To answer this question, we divide the sample countries in Africa into three groups; depending on income per capita in 1999 PPP based US\$. The first group (LOW) includes countries with per capita incomes below $1000 \$^{3}$; the second group (MIDDLE) comprises countries with per capita incomes between 1000US\$ and 2000US\$ $\$$; the third group (HIGH) includes countries with per capita incomes above 2000US\$.

Table 3 reports the minimum, maximum and median of a set of health outcome indicators for these three groups. The last three columns report the medians. The results are unsurprising: higher income per capita is associated with better health outcomes. Life expectancy rises from 48.8 years in the low-income group to 64.2 years in the highincome group, with one exception (low birth weight children in middle income countries) all other outcome medians improve with income, reflecting the positive feedback loop between improved health, improved productivity and income, and improved capacity to provide health services [Pritchett and Summers (1993)]. ${ }^{6}$

\footnotetext{
${ }^{3}$ Congo, Sierra Leone, Tanzania, Burundi, Rwanda, Malawi, Guinea Bissau, Ethiopia, Angola, Zambia, Mali, Niger, Nigeria, Madagascar, Mozambique, Chad, Benin, Democratic Republic of Congo, Burkina Faso, Kenya.

${ }^{4}$ Eritrea, Central African Republic, Uganda, Equatorial Guinea, Djibouti, Sudan, Senegal, Togo, Cameroon, The Gambia, Mauritania, Cote d'Ivoire, Guinea, Ghana.

${ }_{5}^{5}$ Lesotho, Zimbabwe, Morocco, Egypt, Cape Verde, Swaziland, Algeria, Gabon, Namibia, Tunisia, Botswana, South Africa, Mauritius.

${ }^{6}$ Their results suggest there is a structural relationship between income and health with causation running from income to health. They also find that differences in income over the last three decades explain roughly 40 percent of the cross-country differences in mortality improvements.
} 
Table 3: Health Outcomes by Income groups

\begin{tabular}{|l|l|l|l|l|l|l|l|l|l|l|}
\hline & Low & Low & Middle & Middle & High & High & Low & Middle & High \\
\hline & Income & Income & Income & Income & Inc. & Inc. & Income & Income & Income \\
\hline & Min. & Max. & Min. & Max. & Min. & Max. & Median & Median. & Median \\
\hline & & & & & & & & & & \\
\hline Female Life Expectancy & 37.8 & 60.2 & 43.6 & 60.8 & 53.3 & 66.3 & 49.1 & 51.6 & 66.3 \\
\hline Male Life Expectancy & 34.8 & 56.7 & 43.9 & 56.7 & 50.3 & 68.1 & 45.3 & 48.9 & 61.4 \\
\hline Total Life Expectancy & 38.4 & 58.4 & 41.7 & 58.7 & 54.7 & 70.6 & 48.8 & 50.0 & 64.2 \\
\hline & & & & & & & & & & \\
\hline Infant Mortality Rate & 58.0 & 179.4 & 55.7 & 131.3 & 16.1 & 88.6 & 111.8 & 96.6 & 55.3 \\
\hline Mortality Rate Age <5 & 90 & 236 & 86 & 220 & 20 & 145 & 184 & 159 & 75 \\
\hline Maternal Mortality Rate & 490 & 939 & 430 & 1100 & 50 & 400 & 590 & 580 & 200 \\
\hline & & & & & & & & & \\
\hline Low Birth Weight & 10.0 & 18.0 & 5.0 & 35.0 & 7.0 & 15.0 & 13.0 & 14.5 & 9.7 \\
\hline Malnutrition in Children & 22.3 & 50.0 & 13.6 & 44.0 & 9.0 & 26.0 & 30.1 & 23.5 & 10.6 \\
\hline
\end{tabular}

The first six columns report the maximum and minimum within each country group. The overall positive link between outcomes and income is preserved. However, a comparison of low income and middle-income countries reveals that the best performers in the low-income countries achieved better outcomes than the worst performers in the middle-income group. More surprisingly, the same result holds for a comparison of low and high income countries: the best performers in the low income per capita group have achieved comparable if not better health outcomes than the worst performers in the high income group.

Table 4 provides background information on one potential cause of the differences, health spending and access to health services. Again, the first six columns report the maximum and minimum values for the three groups, while the last three columns report the medians. The results match the findings of Table 3. Overall, the provision of health services increases with income per capita. In comparable PPP adjusted US\$, the median low-income country spends 22 US\$ per inhabitant, while the median middle and high-income country spend 50 US\$ and 310 US\$. Across most other indicators, the median values display the same positive relationship with income. Overall, higher spending is thus, not surprisingly, associated with improved health service outputs. 
Comparing the first six columns, it is however again striking that the best performing low-income country commits more resources compared not only to the worst performing middle-income country but also the worst performing high-income country. The results are suggestive of sharp differences in the mapping between financial resources spent on health care and health services ultimately delivered to the population. ${ }^{7}$

Table 4: Health System Resources and Outputs by Income Groups

\begin{tabular}{|l|l|l|l|l|l|l|l|l|l|}
\hline & Low & Low & Middle & Middle & High & High & Low & Middle & High \\
\hline & Inc. & Inc. & Income & Income & Inc. & Inc. & Income & Income & Income \\
\hline & Min. & Max. & Min. & Max. & Min. & Max. & Median & Median. & Median \\
\hline Health Spending & & & & & & & & & \\
\hline - as \% of GDP Total & 0.7 & 7.9 & 2.2 & 5.2 & 3.5 & 7.4 & 3.3 & 3.8 & 5.3 \\
\hline - as \% of GDP Public & 0.2 & 4.0 & 1.0 & 2.9 & 0.6 & 3.8 & 1.7 & 1.8 & 3.0 \\
\hline - per capita in PPP US\$ & 6 & 62 & 15 & 83 & 124 & 571 & 22.5 & 50 & 310 \\
\hline & & & & & & & & & \\
\hline Access (\% of Population) & & & & & & & & & \\
\hline - to health care & 24 & 93 & 45 & 76 & 55 & 99 & 55 & 70 & 90 \\
\hline - to essential medicines & 10 & 65 & 15 & 100 & 30 & 95 & 50 & 70 & 80 \\
\hline - to safe water (total) & 24 & 70 & 7 & 82 & 57 & 100 & 42 & 50 & 67 \\
\hline - to safe water (rural) & 8 & 63 & 24 & 86 & 17 & 66 & 42 & 62 & 42 \\
\hline - to safe water (urban) & 18 & 97 & 48.5 & 97 & 80 & 100 & 75 & 77 & 99 \\
\hline - to essential sanitation (total) & 9 & 86 & 6 & 60 & 11 & 100 & 22 & 37 & 56 \\
\hline - to essential sanitation (urban) & 11 & 97 & 12 & 85 & 20 & 100 & 63 & 59 & 90 \\
\hline & & & & & & & & & \\
\hline Immunization Rates & & & & & & & & & \\
\hline - DPT & 18 & 98 & 40 & 93 & 48 & 96 & 57 & 67 & 78 \\
\hline - Measles & 24 & 99 & 31 & 88 & 50 & 94 & 54 & 66 & 78 \\
\hline & & & & & & & & & \\
\hline Contraceptive Use & 4 & 39 & 2 & 24 & 16 & 75 & 7.7 & 14.0 & 49.0 \\
\hline Doctors per 1000 Pop. & 0.0 & 0.3 & 0.0 & 0.2 & 0.1 & 2.1 & 0.1 & 0.1 & 0.5 \\
\hline Hospital beds per 1000 Pop. & 0.1 & 3.4 & 0.4 & 2.6 & 0.5 & 3.2 & 1.1 & 0.9 & 1.9 \\
\hline
\end{tabular}

A substantial body of work suggests that declines in the mortality rates (in particular for children) are to a large extent driven by improved prevention in addition to improved treatment, consequently, the extent to which the population has access to clean water and sanitation is likely to influence health outcomes [Savedoff et al. (2000)] even for a given health service infrastructure. As Table 4 reveals, relative access rates differ

\footnotetext{
${ }^{7}$ Some caution regarding the precision and cross-country comparability of data, in particular for nonbudget measures such as the access variables, is warranted.
} 
dramatically across countries, with the best access rates among the poorest countries again exceeding the lowest access rates among the high income group.

Table 5 reports matching statistics on two other variables widely thought to affect health outcomes: broad access to education, in particular for women who provide the majority of in-family health services; and the ability of poorer families to pay for health services. Both of the patterns evident in the previous two tables are again present: most indicators improve with median income across the three groups (though there is a suggestion of a U-curve relationship for some variables); while the best performing poor countries again display better education statistics than the worst performing high income countries.

Table 5: Other Health Determinants by Income groups

\begin{tabular}{|l|l|l|l|l|l|l|l|l|l|l|}
\hline & Low & Low & Middle & Middle & High & High & Low & Middle & High \\
\hline & Inc. & Inc. & Income & Income & Inc. & Inc. & Income & Income & Income \\
\hline & Min. & Max. & Min. & Max. & Min. & Max. & Median & Median. & Median \\
\hline & & & & & & & & & & \\
\hline Illiteracy & 21.8 & 86.4 & 19.0 & 66.9 & 14.9 & 56.3 & 45.1 & 51.0 & 29.5 \\
\hline Illiteracy Female & 28.0 & 93.4 & 31.9 & 78.1 & 18.0 & 69.0 & 58.2 & 64.2 & 38.9 \\
\hline Education Spending/GDP & 0.7 & 6.5 & 0.9 & 5.1 & 2.9 & 9.1 & 2.3 & 3.2 & 5.1 \\
\hline Primary Enrollment & 25 & 97 & 36 & 107 & 69 & 136 & 70 & 60.5 & 114 \\
\hline - Female & 19 & 92 & 24 & 86 & 56 & 139 & 59 & 50 & 111 \\
\hline Secondary Enrollment & 4 & 28 & 11 & 36 & 8 & 75 & 10 & 16.5 & 50.5 \\
\hline - Female & 2 & 25 & 5 & 28 & 29 & 77 & 6 & 12 & 54 \\
\hline & & & & & & & & & \\
\hline Gini & 28.9 & 62.9 & 32.7 & 61.3 & 28.9 & 60.9 & 47.1 & 39.8 & 48.1 \\
\hline Income Share Bottom 20\% & 1.1 & 9.7 & 2.0 & 8.4 & 2.7 & 9.8 & 5.1 & 6.4 & 5.0 \\
\hline
\end{tabular}

Table 6 reports the ranking of health service indicators by life expectancy. ${ }^{8}$ The sample countries are again divided into three groups. The first group ${ }^{9}$ (LOW) comprises countries with life expectancies below 50 years, the second group ${ }^{10}$ (MIDDLE) includes

\footnotetext{
${ }^{8}$ Gwatkin et al (2000) provide a broader picture on many of the other factors that can effect health status.

${ }^{9}$ Guinea-Bissau, Rwanda, Sierra Leone, Uganda, Malawi, Guinea, Zambia, The Gambia, Mozambique, Niger, Angola, Eritrea, Chad, Central African Republic, Burkina Faso, Equatorial Guinea, Ethiopia, Burundi, Mali, Djibouti.

${ }^{10}$ Senegal, Benin, Tanzania, Congo, Mauritania, Madagascar, Congo Democratic Republic, Nigeria, Sudan, Gabon, Cote d'Ivoire, Togo, Cameroon, Zimbabwe, Swaziland, Kenya, Ghana, Namibia.
} 
countries with life expectancies between 50 and 60 years, and the last group ${ }^{11}$ (HIGH) comprises countries with life expectancies above 60 years.

Table 6: Health System Resources and Outputs by Life Expectancy

\begin{tabular}{|l|l|l|l|l|l|l|l|l|l|}
\hline & Low & Low & Middle & Middle & High & High & Low & Middle & High \\
\hline & Min. & Max. & Min. & Max. & Min. & Max. & Median & Median & Median \\
\hline Health Spending & & & & & & & & & \\
\hline - as \% of GDP Total & 1.3 & 7.9 & 0.7 & 7.4 & 3.5 & 7.1 & 3.7 & 4.2 & 4.5 \\
\hline - as \% of GDP Public & 0.6 & 4.0 & 0.2 & 3.8 & 1.3 & 3.7 & 1.9 & 1.6 & 2.9 \\
\hline - per capita in PPP US\$ & 7 & 50 & 6 & 399 & 124 & 571 & 31 & 66 & 310 \\
\hline & & & & & & & & & \\
\hline Access (\% of Population) & & & & & & & & & \\
\hline - to health care & 24 & 80 & 42 & 93 & 62 & 99 & 37 & 67 & 94 \\
\hline - to essential medicines & 20 & 93 & 10 & 100 & 51 & 95 & 58 & 65 & 80 \\
\hline - to safe water (total) & 7 & 61 & 25 & 82 & 57 & 100 & 38 & 56 & 70 \\
\hline - to safe water (rural) & 17 & 86 & 8 & 85 & 17 & 67 & 45 & 44 & 53 \\
\hline - to safe water (urban) & 18 & 97 & 48 & 99 & 100 & 100 & 78 & 80 & 100 \\
\hline - to essential sanitation (total) & 6 & 63 & 9 & 86 & 11 & 100 & 33 & 36 & 55 \\
\hline - to essential sanitation (urban) & 12 & 82 & 11 & 98 & 20 & 100 & 58 & 69 & 91 \\
\hline & & & & & & & & & \\
\hline Immunization Rates & & & & & & & & & \\
\hline - DPT & 18 & 98 & 35 & 96 & 56 & 93 & 57 & 69 & 78 \\
\hline - Measles & 24 & 99 & 31 & 94 & 66 & 92 & 58 & 62 & 82 \\
\hline & & & & & & & & & \\
\hline Contraceptive Use & 2 & 21 & 6 & 48 & 16 & 75 & 8 & 17 & 50 \\
\hline Doctors per 1000 Pop. & 0.0 & 0.2 & 0.0 & 0.3 & 0.1 & 2.1 & 0.0 & 0.1 & 0.6 \\
\hline Hospital beds per 1000 Pop. & 0.1 & 1.7 & 0.2 & 3.4 & 1.0 & 3.1 & 0.9 & 1.3 & 1.9 \\
\hline
\end{tabular}

Based on the medians, the table reveals a positive association between resources devoted to the health care sector and health sector outputs, measured by access rates and immunization rates. More resources devoted to health care and greater output of health care services are also associated with higher life expectancy. Comfortingly, the table is thus consistent with the view that an increase in resources devoted to health care will (in most instances) improve public health.

As before, the ranges reported in the first six columns suggest that these linkages are far from uniform, in two senses. First, the link between spending measures and outputs of health services is quite unstable. Several countries with per capita health

\footnotetext{
${ }^{11}$ Lesotho, Egypt, South Africa, Cape Verde, Morocco, Botswana, Tunisia, Algeria, Mauritius.
} 
expenditures below $50 \$$ report immunization and access rates above those of countries spending several times more on health care per capita. While not the main theme of our paper, the finding suggests that a substantial improvement in health service provision may be obtained at moderate financial cost in some countries.

Table 7: Other Health Determinants by Life Expectancy

\begin{tabular}{|l|l|l|l|l|l|l|l|l|l|}
\hline & Low & Low & Middle & Middle & High & High & Low & Middle & High \\
\hline & Min. & Max. & Min. & Max. & Min. & Max. & Median & Median. & Median \\
\hline & & & & & & & & & \\
\hline Illiteracy & 19 & 86 & 15 & 67 & 17 & 56 & 53 & 37 & 30 \\
\hline Illiteracy Female & 29 & 93 & 18 & 77 & 18 & 69 & 67 & 47 & 43 \\
\hline Education Spending/GDP & 1.5 & 5.4 & 0.7 & 9.1 & 3.1 & 8.6 & 2.3 & 4.0 & 5.1 \\
\hline Primary Enrollment & 25 & 97 & 52 & 136 & 69 & 118 & 63 & 77 & 107 \\
\hline - Female & 19 & 92 & 26 & 139 & 56 & 122 & 41 & 70 & 110 \\
\hline Secondary Enrollment & 4 & 16 & 5 & 52 & 8 & 75 & 10 & 23 & 52 \\
\hline - Female & 2 & 13 & 4 & 54 & 29 & 77 & 5 & 16 & 55 \\
\hline & & & & & & & & & \\
\hline Gini & 28.9 & 62.9 & 32.7 & 60.9 & 28.9 & 59.3 & 48.0 & 42.9 & 39.9 \\
\hline Income Share Bottom 20\% & 1.1 & 9.7 & 2.7 & 8.4 & 2.8 & 9.8 & 5.0 & 5.7 & 6.2 \\
\hline & & & & & & & & & \\
\hline Military Expenditure/GDP & 1 & 20 & 1 & 5 & 0.35 & 5 & 2.8 & 2.0 & 2.65 \\
\hline Debt/GDP & 28 & 340 & 16 & 325 & 13 & 64 & 63 & 89 & 52 \\
\hline Government Consump.GDP & 7.5 & 47 & 6.6 & 31 & 12.3 & 32 & 12.8 & 11.2 & 16.4 \\
\hline
\end{tabular}

Second, several countries with life expectancies below fifty years report immunization rates and rates of access to clean water, sanitation and health care that are significantly above those reported by countries with life expectancies above 60 years. The link between resources devoted to health care, the output of medical services generated by these resources, and the effect of these services on at least some measures of public health thus appears to be far from linear. ${ }^{12}$

Finally, Table 7 reports statistics for a number of other variables that might be thought to be associated with life expectancy. Commencing with the median, education variables uniformly improve with life expectancy, as does the income share of the bottom twenty percent of population. In both cases, causality presumably is two-sided. No clear unconditional linkage emerges for military expenditures, the debt to GDP ratio or

\footnotetext{
${ }^{12}$ See Hammer (2000) for a case study of Zambia.
} 
government consumption. Considering the distribution statistics, very substantial variation is again apparent: several countries with low life expectancies boast education levels above those of countries with much higher life expectancies, similar variation is observed for the other variables.

\section{Classification Tree Analysis}

The stylized facts reported above suggest a positive unconditional association between life expectancy and income per capita, as well as a positive association between health service outputs and income per capita. One interpretation of the results is that the primary determinant of life expectation is income per capita. Yet, the substantial variation documented in the preceding section suggests that while an important determinant, poverty is not destiny as far as life expectancy is concerned. We now examine the linkages between health spending, health service outputs, other determinants and life expectancy in a cross section framework. We use a classification tree methodology to allow for the likely presence of non-linearity. In essence, a classification tree provides a useful way of characterising a binary variable with respect to a set of potential associated factors. The dependent variable is high (1) and low (0) life expectancy. High life expectancy is defined as the top third of observations in the sample (life expectancies above 55.7 years). Low life expectancy is defined as the bottom third of observations (life expectancies below 49 years). Both groups have sixteen observations. The middle third is dropped to provide contrast.

The resulting classification rule is presented in Table 8. The figure in brackets provides the probability (relative to the overall sample). The figures on each node provide the number of observations. The single best predictor of high versus low mortality is the percentage of population with access to health care, with a threshold of $50 \%$. For those countries falling below the threshold, a high female secondary enrolment ratio lifts the chance of belonging to the HIGH group to one third, while countries with low access rates and low female secondary enrolment rates have a less than $10 \%$ chance of being in the high life expectancy group. 
Table 8. Classification Tree (CART): Incidence of High versus Low Life Expectancy

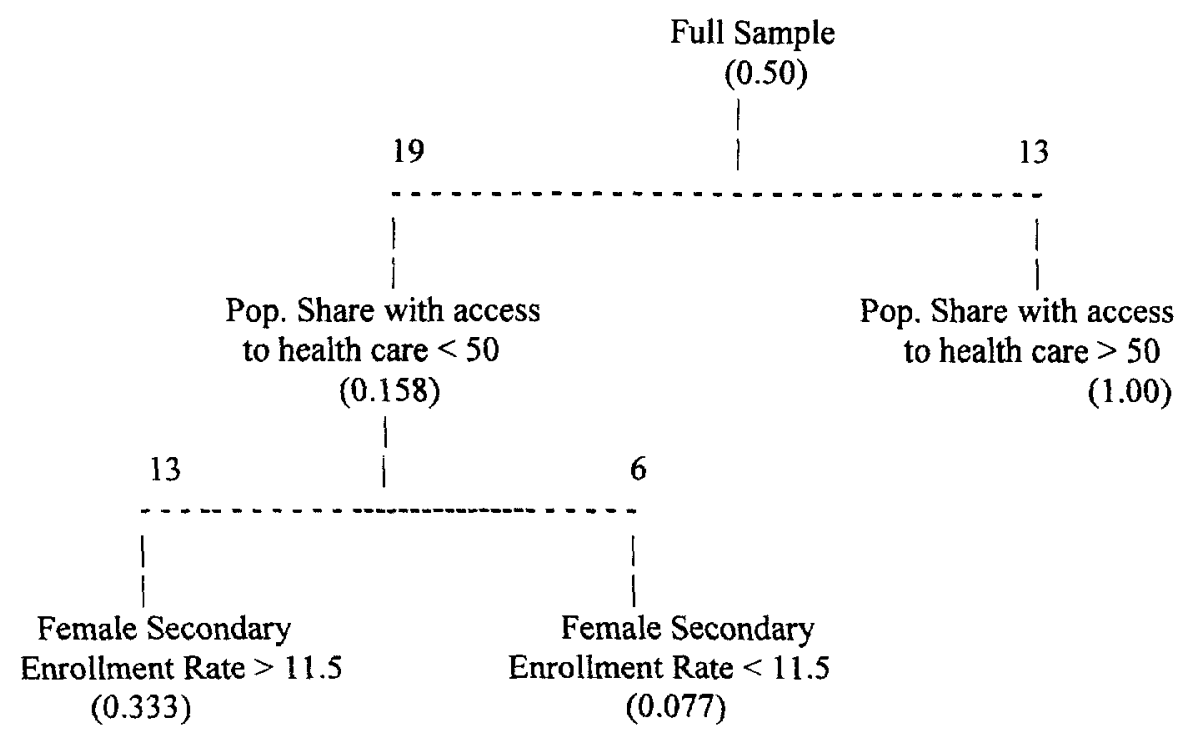

The methodology also provides a ranking of the relative importance of all variables, which takes into account the relative quality of each variable at all thresholds. Thus, a variable that never is the single best discriminant at any node (and thus does not appear in the tree) might be ranked second at several nodes, and thus have high discriminatory power between the two groups. Table 9 reports the relative importance, with the score for the first variable set equal to 100 . 
Table 9: Relative Power as Discriminants

\begin{tabular}{|l|l|}
\hline Variable & Importance \\
\hline Share of population with access to health care & 100 \\
\hline GNP per capita (US\$ PPP adjusted) & 68 \\
\hline Fertility rate & 66 \\
\hline Share of population with access to safe water & 49 \\
\hline Institutional Investor risk rating & 33 \\
\hline Female secondary enrolment ratio & 17 \\
\hline Public spending on health care & 11 \\
\hline Total illiteracy ratio & 11 \\
\hline Male illiteracy ratio & 11 \\
\hline Primary enrolment ratio & 10 \\
\hline & \\
\hline
\end{tabular}

The share of population with access to health care is the best overall discriminant, followed by GNP per capita, the fertility rate and the share of population with access to safe water. Income is thus an important determinant of life expectancy (and vice versa), but it is not destiny, as above average provision of access to health care and safe water themselves not exclusively determined by income, as revealed in Table 3 - can sharply effect life expectancy.

\section{Conclusion}

Is poverty destiny, as far as health outcomes are concerned? We addressed this question by assessing life expectancy in Africa. While health outcomes are positively correlated with income, the link is far from uniform. Indeed, several of the poorest 
African countries boast better health outcomes compared to countries with much higher income levels. Nor does health expenditure, either as percentage of GNP or per capita, appear to be a particularly good predictor of health outcomes (leaving aside the endogeneity issue).

The key variable associated with good health outcomes ${ }^{13}$ (controlling for health expenditures) are access rates --- to health services, to clean water and sanitation, and last but not least to education, particularly for women. While we do not examine formally, the findings suggest that, for given expenditure rates, the benefits of allocating greater shares to improving access warrant further study ${ }^{14}$ [Hammer (2000)].

To be sure, modesty is required in drawing any policy implications from as aggregate a dataset as the one explored here. Apart from data problems, we look at a single year, and thus cannot easily account for the complex dynamic linkages between health system inputs, outputs, development and health outcomes; nor can we establish causality patterns. That said, the instability of the link between health expenditures, health service outputs and health outcomes suggests marked differences in the mapping from spending to services, and from services to outcomes, and suggests productivity enhancement of health service provision as an important aspect. Among the pertinent questions here is the best division of health care spending between public sources, NGOs and households; the appropriate shares of public expenditures devoted to preventive relative to curative measures; and the relative importance attached to sanitation infrastructure versus traditional health care.

${ }^{13}$ Our study was focussed on the national level. We thus do not take account of cross-national aspects of disease transmission (river pollution) or disease prevention and treatment. There have been a number of success stories in co-ordinated health measures, including sharp reductions in smallpox, river blindness and polio. A cross-national perspective on improving health is thus increasingly seen as an essential component of a global health strategy [Sachs (2000)] and may yield benefits on top of those obtainable by the national measures discussed here.

${ }^{14}$ Hammer (2000) provides a revealing case study of Zambia. Morocco provides an illustration of a high income country with a low population share with access to clean water, while Tanzania provides an example of the opposite case, perhaps not accidentally, the relative health outcome for Morocco and Tanzania are at the bottom and at the top of their respective peer groups. 


\section{References}

Easterly, William. "Life during Growth" 1999. Journal of Economic Growth 4 (3) September: 239-275

Garenne Michel, Gakusi Eneas, (2000), Health effects of structural adjustment programs in sub-Saharan Africa, CEPED, Paris.

Gwatkin, Davidson R. Rustein Shea, Johnson Kiersten, Pande Rohini, Wagstaff Adam, (2000), Socio-Economic Differences in Health, Nutrition, and Population, World Bank.

Hammer Jeffrey, (2000), Zambia, Public Expenditure Review, World Bank, draft.

Huttly,S.R.A.,Morris,S.S., Pisani,V. (1997), Prevention of diarrhea in young children in developing countries, Bulletin of the World Health Organisation,75 (2);163-174

Jack, William, (1999), Principles of heath economics for developing countries, World Bank

Pritchett, Lant, and Lawrence H. Summers. "Wealthier is Healthier."1996. Journal of Human Resources 31 (4): 842-68.

Sachs J. (2000) Chairman of the Commission on Macroeconomics and Health of the WHO, Various progress reports, Paris, France

Savedoff William and Paul Schultz, (2000), Earnings and the elusive Dividends of Health, IDB

Wang, Jia et al. (1998); Measuring Country Performance on Health; Washington, World Bank.

World Development Report (2000/2001), World Bank

World Health Organization, (1999), The World Health Report 1999, Statistical Annex 



\section{Policy Research Working Paper Series}

Title

WPS2655 Measuring Services Trade Liberalization and its Impact on Economic Growth: An Illustration

WPS2656 The Ability of Banks to Lend to Informationally Opaque Small Businesses

WPS2657 Middle-Income Countries: Development Challenges and Growing Global Role

WPS2658 How Comparable are Labor Demand Elasticities across Countries?

WPS2659 Firm Entry and Exit, Labor Demand, and Trade Reform: Evidence from Chile and Colombia

WPS2660 Short and Long-Run Integration: Do Capital Controls Matter?

WPS2661 The Regulation of Entry

WPS2662 Markups, Entry Regulation, and Trade: Does Country Size Matter?

WPS2663 Agglomeration Economies and Productivity in Indian Industry

WPS2664 Does Piped Water Reduce Diarrhea for Children in Rural India?

WPS2665 Measuring Aggregate Welfare in Developing Countries: How Well Do National Accounts and Surveys Agree?

WPS2666 Measuring Pro-Poor Growth
Author

Date

August 2001

Aaditya Mattoo

Randeep Rathindran

Arvind Subramanian

Allen N. Berger

Leora F. Klapper

Gregory F. Udell

Peter Fallon

Vivian Hon

Zia Qureshi

Dilip Ratha

Pablo Fajnzylber

William F. Maloney

Pablo Fajnzylber

William F. Maloney

Eduardo Ribeiro

Graciela Kaminsky

Sergio Schmukler

Simeon Djankov

Rafael La Porta

Florencio Lopez de Silanes

Andrei Shleifer

Bernard Hoekman

Hiau Looi Kee

August 2001

Marcelo Olarreaga

Somik Lall

Zmarak Shalizi

Uwe Deichmann

Jyotsna Jalan

Martin Ravallion

Martin Ravallion

August 2001

August 2001

August 2001

August 2001

August 2001

August 2001

August 2001

August 2001

August 2001

Martin Ravallion
Contact

for paper

A. Yaptenco 31823

D. Fischer 38656

A. Pillay 88046

A. Pillay 88046

E. Khine 37471

R. Vo 33722

L. Tabada 36896

R. Yazigi 37176

C. Cunanan 32301

C. Cunanan 32301
C. Cunanan 32301 
Policy Research Working Paper Series

Title

WPS2667 Trade Reform and Household Welfare: Elena lanchovichina The Case of Mexico
Author Alessandro Nicita Isidro Soloaga
Contact

for paper

August 2001

L. Tabada 36896 